Campos Neutrais - Revista Latino-Americana de Relações Internacionais Vol. 1, No 2, p. 91-106, Maio- Agosto de 2019

\title{
A construção do agronegócio na região de planejamento sudoeste goiano
}

Roberto Eduardo Castillo Pizarro ${ }^{1}$

Fernando Luis Araújo Sobrinho ${ }^{2}$

Resumo: A Região de Planejamento do Sudoeste Goiano passa por importantes transformações espaciais a partir da década de 1970 com a introdução das técnicas e tecnologias da modernização da agricultura a qual introduz as lavouras de grãos (arroz, soja e milho), impactos socioambientais e novas relações capital e trabalho. A industrialização da agricultura concretizou a cadeia produtiva de grãos e seus derivados semielaborados como farelo e óleo de soja, rações e ampliação da capacidade de armazenamento. O agronegócio concretiza-se no espaço da região no final da década de 1990 com a instalação de unidade agroindustrial de empresa multinacional brasileira e impôs novas relações no campo por meio do sistema de produção integrado de aves e suínos. Todos os processos de transformações do campo do Sudoeste Goiano foram resultados das ações das políticas e financiamentos públicos.

Palavras-chave: modernização da agricultura, industrialização da agricultura, agronegócio, sudoeste goiano

\section{La construcción de agronegocios en la región de planificación del Suroeste Goiano}

Resumen:La región de planificación del Sudoeste Goiano ha experimentado importantes transformaciones espaciales desde la década de 1970 con la introducción de técnicas y tecnologías de modernización agrícola que introducen cultivos de granos (arroz, soya y maíz), impactos sociales y ambientales, nuevas relaciones de capital y trabajo. La industrialización de la agricultura materializó la cadena de producción de granos y sus derivados semielaborados, como la harina y el aceite de soja, la alimentación y la expansión de la capacidad de almacenamiento. El agronegocio tuvo lugar en la región a fines de la década de 1990 con la instalación de una unidad agroindustrial de una multinacional brasileña e impuso nuevas relaciones en el campo a través del sistema integrado de producción avícola y porcina. Todos los procesos de transformación del campo del Sudoeste Goiano fueron el resultado de las acciones de las políticas públicas y la financiación por recursos estatales.

Doutorado em Geografia pela Universidade de Brasília.

Doutorado em Geografia pela Universidade Federal de Uberlândia. 
Campos Neutrais - Revista Latino-Americana de Relações Internacionais

Vol. 1, No 2, p. 91-106, Maio- Agosto de 2019

Palabras clave: modernización de la agricultura, industrialización de la agricultura, agronegocios, sudoeste goiano

\section{Introdução}

A Região de Planejamento do Sudoeste Goiano (Mapa 1: Regiões de Planejamento do Estado de Goiás) é a principal produtora de proteínas vegetais (grãos: soja e milho) e animais (aves e suínos) do estado de Goiás. O espaço geográfico da região passou por grandes transformações, principalmente, com as aplicações das políticas públicas que fomentaram e permitiram a implantação das lavouras mecanizadas de grãos e de empresas privadas a partir da década de 1970. As áreas rurais antes ocupadas pelas lavouras de arroz de sequeiro, feijão e pastagens para os bovinos de corte e leite deram lugar para as lavouras de grãos. As máquinas substituíram as pessoas no trabalho do campo, algumas cidades cresceram tanto no número de habitantes como nos seus problemas em atender as necessidades básicas de saúde, habitação, segurança, educação e transporte. O critério para delimitar a Região de Planejamento do Sudoeste Goiano são os eixos rodoviários: a BR060 (ligação da região até a capital Goiânia e o Distrito Federal) e a BR452 (rodovia de Rio Verde - Itumbiara, divisa com o estado de Minas Gerais). Essas rodovias e a presença do porto de São Simão (hidrovia Tietê-Paraná) permitem a escoação da produção agroindustrial do Sudoeste Goiano para os centros consumidores do Sudeste brasileiro e para os portos de Santos e Paranaguá que despacham a produção para o mercado internacional. (IMB, 2006) 
Mapa 1: Regiões de Planejamento do Estado de Goiás

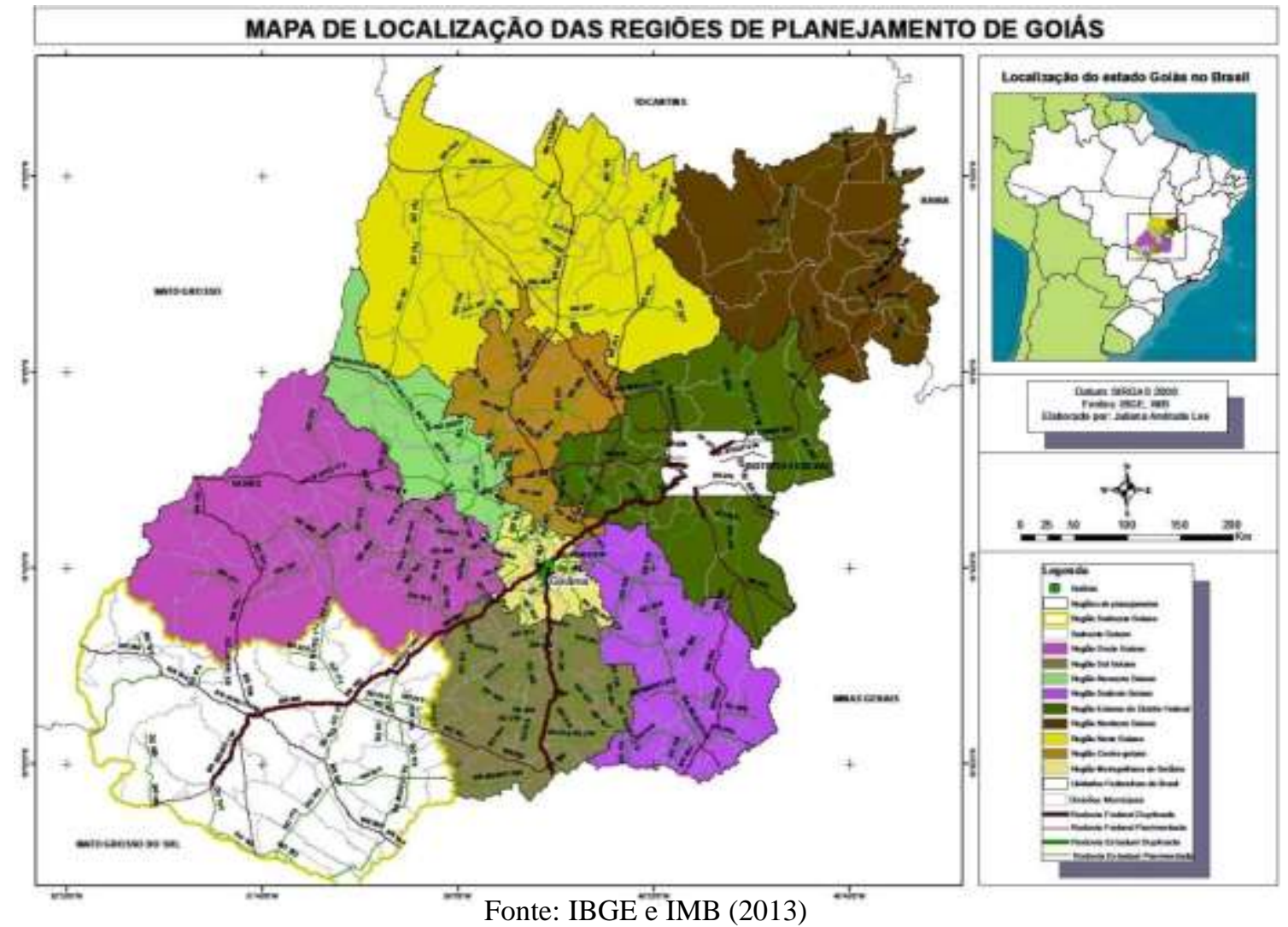

A Marcha para o Oeste (década 1930-40) e a construção de Brasília (década de 1950/60) permitiram a construção de infraestrutura e da intensificação das relações capitalistas até então presentes nas grandes cidades do período como São Paulo e Rio de Janeiro. Essas transformações da Região Centro-Oeste e no Sudoeste Goiano viabilizaram não apenas a inserção dos equipamentos de produção como a ideologia do desenvolvimento e progresso vias as formas capitalistas de produção representadas com tecnologias, assalariamento, urbanização, consumo, indústrias e novos produtos, no caso, agropecuários.

Da modernização da agricultura ao agronegócio as atividades econômicas só foram viáveis devido as ações decisivas das políticas públicas federais e estaduais as quais davam financiamentos com juros subsidiados, investimentos públicos em infraestrutura, isenções fiscais a produção agropecuária e agroindustrial etc.

O objetivo deste trabalho é caracterizar a modernização da agricultura iniciada no final da década de 1960, industrialização da agricultura (anos 1980 e início do século XXI) e o atual agronegócio o qual introduziu novas atividades agroindustriais na região como a cadeia produtiva de grãos-aves-suínos com instalação de grande indústria transnacional de capital nacional. 
Campos Neutrais - Revista Latino-Americana de Relações Internacionais

Vol. 1, No 2, p. 91-106, Maio- Agosto de 2019

\section{Da modernização da agricultura ao agronegócio}

A Região de Planejamento Sudoeste Goiano não teve no espaço a articulação das atividades mineradoras do século XVIII como na porção norte do estado de Goiás. Segundo pesquisadores a região era um grande vazio econômico e demográfico, mas os trabalhos de Barbosa (2002) e Lourdeau (2015) destacam os sítios arqueológicos da área Nuclear de Caiapônia e Mineiros sendo comprovada a presença de grupos humano na região e assim, eliminando a ideia de vazio populacional.

As atividades agropastoris do século XIX e início do século XX deram origem a cidades importantes do Sudoeste Goiano como Rio Verde (1854), Jataí (1882), Mineiros (1905) e Quirinópolis (1943). (TEIXEIRA NETO, 2009) (IMB, 2006)

Para Chaul (1997, p. 89),

[...] o setor da pecuária pode ser considerado como uma ilha no mar de estagnação econômica que se abateu sobre Goiás com o fim da mineração. Era o setor mais adequado às condições econômicas gerais da região. Afinou-se bem mais com as condições gerais do período pós-mineratório.

Por outro lado, as maiores barreiras para a articulação da pecuária goiana residiam em problemas como os altos custos com frete, sal e as grandes distâncias em relação aos mercadores consumidores. Não menos importante para estagnação econômica do estado e do Sudoeste Goiano, era a reduzida capitalização dos produtores no ato da comercialização. O gado bovino produzido em Goiás era comprado por grandes atravessadores por preços baixos e levados para cidades do Triângulo Mineiro como Uberaba e Uberlândia.

Os incentivos das políticas públicas para a ocupação e a implantação da pecuária bovina no Sudoeste Goiano são iniciados com a lei $\mathrm{n}^{\circ} 11$, de 05 de setembro de 1838, a qual isentava por um período de 10 anos o pagamento dos Dízimos de Miunças e impostos da criação de gado bovino e equino aos habitantes já fixados e os que lá se fossem estabelece. Assim a pecuária bovina se desenvolveu tornando o Sudoeste Goiano região de destaque econômico nas suas atividades do comércio de bovinos.

A ferrovia em Goiás data dos primeiros anos do século XX quando a agricultura do sul do estado deixa ser apenas de subsistência e passa a exportar, por exemplo, fumo. O gado bovino representava a principal atividade econômica e, ainda, destacavam-se as exportações de arroz, charque, couros, suínos, toucinho e borracha. No ano de 1910 é iniciada a construção da Estrada de Ferro Goiás como ponto de partida a cidade de Araguari no Triângulo Mineiro. Até 1915 a Estrada de Ferro chegara apenas até a margem do rio 
Corumbá, as obras da construção da ponte ficaram paradas até 1921 e no ano de 1922 a linha chega ao atual município de Vianópolis. (BERTRAN, 1988)

As ações da Marcha para o Oeste de ocupar o interior do Brasil era introduzir os padrões capitalistas dos principais centros urbanos da região Sudeste, essencialmente das cidades de São Paulo e Rio de Janeiro, seriam implantado/reproduzidos no interior do país com o objetivo de integrá-los e desenvolvê-los na economia nacional. Além da Marcha para Oeste a construção de Brasília e o Plano de Metas fundamentaram-se na entrada do capital privado na economia por meio da substituição das importações com a produção industrial de bens de consumo e, os investimentos públicos na implantação de indústrias de base e a construção da infraestrutura.

A construção de Brasília e o Plano de Metas do Governo de Juscelino Kubitschek (1956-1961) criaram impactos diretos no espaço geográfico de Goiás. A construção de infraestrutura (rodovias, rede elétrica, telecomunicações etc.) viabilizou o funcionamento das atividades burocráticas da capital, como também iniciou a interligação com os mais variados pontos do país até o centro do poder político.

Para atingir seus objetivos, segundo Almeida (2004, p.165), o Plano de Metas era compreendido em 30 metas entre elas:

1) Energia (com $43,4 \%$ do investimento total): elétrica; nuclear; carvão mineral; produção e refinação de petróleo; 2) Transportes $(29,6 \%$ dos recursos previstos): reaparelhamento e construção de ferrovias; pavimentação e construção de rodovias; serviços portuários e de dragagens; marinha mercante; transportes aeroviários; 3) Alimentação (com apenas 3,2\% dos investimentos previstos): trigo; armazéns e silos; armazéns frigoríficos; matadouros industriais; mecanização da agricultura; fertilizantes; 4) Indústrias de base (com 20,4\% dos investimentos previstos): siderurgia; alumínio; metais nãoferrosos; cimento; álcalis; celulose e papel; borracha; exportação de minérios de ferro; indústria automobilística; construção naval; mecânica e material elétrico pesado; 5) Educação (3,4\% dos recursos): formação de pessoal técnico

A construção de Brasília por meio da expansão das redes de comunicação, transporte e energia fomentou a imigração para o Centro-Oeste. Portanto, essa articulação do espaço permitiu ondas migratórias e a inserção da região no cenário econômico nacional e internacional. (FREDERICO, 2010)

Santos (2007, p.130) afirma sobre a construção de Brasília como novo pacto territorial: 
Ela se inscreve em um movimento bem mais amplo, o da modernização do país, cujo território devia se equipar de um modo adequado à enorme mudança programada. Equipam-se alguns pontos privilegiados, mediante uma obra consistente de renovação urbana e o próprio território como um todo é chamado a ter mais fluidez.

Indica Santos que o capitalismo exigia um Estado mais dinâmico e moderno, com território no qual as "ordens e mensagens" chegassem com eficiência. Todos esses investimentos em infraestrutura são as justificativas para dinamizar os fluxos de capitais, pessoas, dados, mercadorias etc. Porém, característica deste processo é a presença de monopólios e oligopólios nacionais ou internacionais para as novas áreas do mercado as quais são confundidas com os "próprios limites geográficos, facilitando a concentração econômica, e a concentração espacial.”. (2007, p. 131)

As obras relevantes para o estado de Goiás realizado pelo Plano de Metas foram a BR060, que liga o Sudoeste Goiano até Brasília, e a usina hidrelétrica de Cachoeira Dourada. As principais transformações espaciais do Sudoeste Goiano, como em grande parte do Cerrado, no fim da década de 1960 e início de 1970 foram promovidas pela modernização da agricultura a qual introduziu as lavouras mecanizadas de soja e milho.

A modernização da agricultura viabiliza-se pelos paradigmas da Revolução Verde, segundo Frederico (2010, p.31)

Para promover o aumento da produção e da produtividade agrícola, a partir de meados de 1960, o Estado, por meio de suas instituições de pesquisa e colaboração com empresas multinacionais reestruturou, mesmo que de forma seletiva, o sistema técnico agrícola brasileiro, por meio da implantação do paradigma da Revolução Verde. Este processo foi proposto e implantado por instituições internacionais dos EUA e multilaterais (Fundação Ford, Fundação Rockfeller, Banco Mundial, USAID), com a cooperação de instituições criadas do mundo.

Os elementos da Revolução Verde, por Matos e Pessôa (2011), foram aplicados nos espaços rurais dos EUA e Europa, o aumento dos índices de produtividade tornou-se quase exclusivo parâmetro para afirmar desenvolvimento econômico dos países adotantes das técnicas da Revolução Verde.

O processo de modernização da agricultura fez parte das políticas públicas dos governos militares (1964-1985) com a introdução de novas técnicas e máquinas agrícolas, uso de fertilizantes, agrotóxicos, novas espécies vegetais, territorialização do capital no espaço agrário nacional com o uso de trabalho assalariado, expropriação de recursos naturais, circulação de mercadorias, recursos financeiros públicos para o setor agropecuário e acentuou 
Campos Neutrais - Revista Latino-Americana de Relações Internacionais Vol. 1, No 2, p. 91-106, Maio- Agosto de 2019

as desigualdades regionais com acúmulo de terra e renda (KAGEYAMA;SAQUET, 1990, 2006).

As marcas da modernização da agricultura no Sudoeste Goiano são sentidas com a expansão das lavouras de arroz, milho e soja (Gráfico 1). A região é colocada no cenário da modernização da agricultura por apresentar características físicas e de estrutura agrária própria para o desenvolvimento das lavouras comerciais de grãos em virtude dos seus elementos naturais, terras disponíveis para o aumento rápido da produção de grãos (Arrais, 2013).

Gráfico 1: Sudoeste Goiano: Produção de Arroz, Milho e Soja (ton) 1970-1995

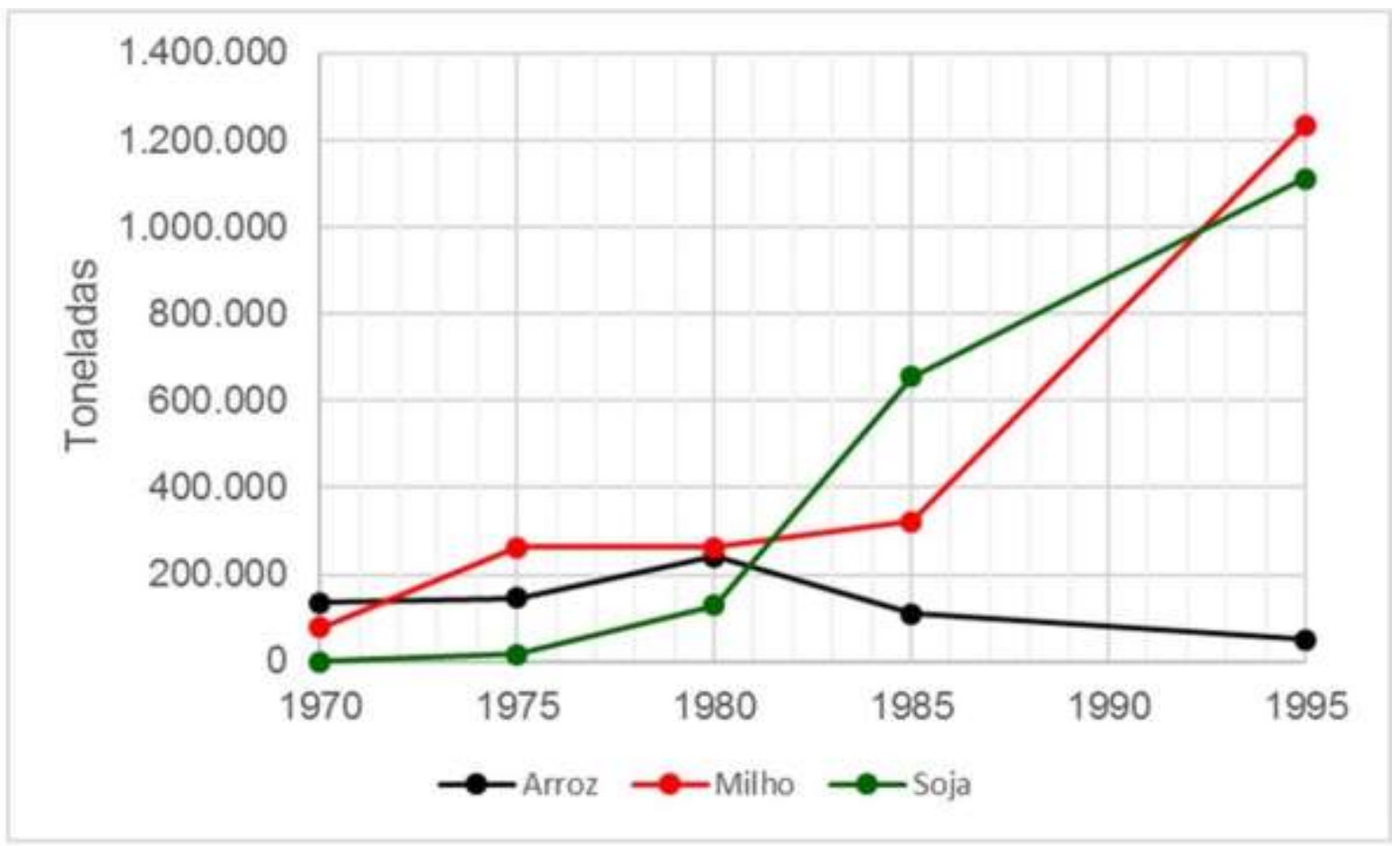

Fonte:Censo Agropecuário (1970, 1975, 1980, 1985, 1995). Organizado pelo autor (2016)

A primeira cultura introduzida nas áreas de cerrado durante o processo de modernização da agricultura foi o arroz. Este produto agrícola é considerado como "amansador" dos cerrados, ou seja, permitiu a melhoria nas condições naturais dos solos, proporcionando posteriormente a introdução, da soja e do milho. Comuns são os relatos de agricultores sobre os primeiros anos da década de 1970: cultivavam o arroz, não apenas para melhorar as condições dos solos, mas por motivos comerciais, os preços na época eram atrativos e os estados da região Sudeste do Brasil eram mercados consumidores certos da produção.

Para Castro e Fonseca (1995), a redução da produção da área de arroz deve-se ao fato de a cultura ser essencial para a abertura da fronteira agrícola, tanto no controle das pragas 
Campos Neutrais - Revista Latino-Americana de Relações Internacionais Vol. 1, No 2, p. 91-106, Maio- Agosto de 2019

através da rotação de cultura para evitar problemas sanitários da monocultura, mas também por ceder espaço para um padrão produtivo elevado e de uma produção estável de grãos em grande escala. Os dados da tabela 1 tornam evidente a redução na acima dos $50 \%$, em números absolutos, a produção passa de 136.022 toneladas em 1970 para apenas 50.007 toneladas no ano de 1995.

Tabela 1: Evolução da Produção Arroz (\%): 1970-1995

\begin{tabular}{ccccc} 
Ano & Brasil & Centro-Oeste & Goiás & Sudoeste Goiano \\
1970 & - & - & - & - \\
1975 & 43,2 & 60,4 & 23,2 & 6,7 \\
1980 & 7,1 & 31,6 & 21,6 & 66,6 \\
1985 & 11,1 & $-39,5$ & $-42,4$ & $-54,5$ \\
1995 & $-10,4$ & $-41,4$ & $-73,9$ & $-54,6$ \\
\hline \multicolumn{5}{r}{}
\end{tabular}

A produção de soja e milho são inversamente proporcionais aos dados da rizicultura do Sudoeste Goiano (tabelas 2 e 3). Os números de crescimento são expressivos, a soja cresce entre 1970-1995 com os seguintes índices: 5.6715, 6345, 403,1\% e 68\%. O milho no Sudoeste Goiano tem a produção com índices menores, porém, não menos significativo: 237\% (1975), 1980 variação menor de 1\%, 22,4\% (1985) e 283\% (1995), números maiores se comparados com a produção brasileira, do Centro Oeste e Goiás com exceção da safra 1980.

Tabela 2: Produção Soja (ton): 1970-1995

\begin{tabular}{ccccc} 
Ano & Brasil & Centro-Oeste & Goiás & Sudoeste Goiano \\
1970 & 1.884 .227 & 24.568 & 10.219 & 307 \\
1975 & 8.721 .274 & 250.160 & 82.173 & 17.717 \\
1980 & 12.757 .962 & 1.509 .861 & 368.477 & 130.136 \\
1985 & 16.730 .087 & 4.646 .369 & 1.157 .704 & 654.686 \\
1995 & 21.563 .768 & 8.246 .281 & 1.960 .112 & 1.111 .334 \\
\hline
\end{tabular}

Fonte: Censos Agropecuários 1970-1995. Organizado pelo autor (2016)

Tabela 3: Produção Milho (ton): 1970-1995

\begin{tabular}{ccccc} 
Ano & Brasil & Centro-Oeste & Goiás & Sudoeste Goiano \\
1970 & 12.770 .216 & 768.379 & 547.432 & 77.856 \\
1975 & 14.343 .556 & 1.315 .983 & 1.090 .193 & 262.552 \\
1980 & 15.722 .581 & 1.565 .805 & 1.277 .414 & 262.586 \\
1985 & 17.774 .404 & 2.010 .987 & 1.507 .916 & 321.409 \\
1995 & 25.510 .505 & 5.616 .168 & 2.971 .570 & 1.232 .195 \\
\hline
\end{tabular}

A estrutura de silos no Sudoeste Goiano não acompanha o crescimento da produção apesar do elevado crescimento do período, se em 1970 existia capacidade para armazenar 
1.308 toneladas de grãos em 1995 a capacidade armazenadora é de 608.257 toneladas, mas relatos de produtores e empresários da região destacavam a necessidade de investimentos em novas unidades armazenadoras e, ainda, registravam-se nos anos 1990 a secagem e guarda provisória da produção de arroz em grandes avenidas das cidades de Rio Verde e Jataí. (ARRAIS, 2013) (BRASIL, 1982)

As técnicas da modernização foram propagadas também pelas cooperativas, no Sudoeste Goiano a COMIGO (Cooperativa Mista dos Produtores Rurais do Sudoeste Goiano) foi uma das responsáveis pela propagação dos chamados pacotes tecnológicosA cooperativa foi utilizada pelo Estado durante as décadas de 1970 e 1980 como instituição de propagação dos pacotes tecnológicos, através de linhas de crédito e assistência técnica. Assim, beneficiou o grande e o médio proprietário/produtor rural ao contrário dos seus ideais cooperativos do século XIX, que propunham um fortalecimento dos trabalhadores, expropriados dos meios de produção em virtude das inovações da Revolução Industrial.

A industrialização da agricultura é o processo de impor aos produtores e produtos agropecuários um padrão de qualidade, quantidade e prazo de entrega definido pela indústria. O campo não é apenas mais um consumidor de produtos industrializados de máquinas e insumos (sementes, fertilizantes, agrotóxicos etc.). A produção agropecuária é a mais que matéria prima padronizada pelos critérios industriais, por prazos de contratos de compra e venda das indústrias, o campo, agora, produz bens intermediários para as mais variadas indústrias, segundo Kageyama et al. (1990).

É possível afirmar que a industrialização da agricultura do Sudoeste Goiano ocorre com a implantação da unidade esmagadora e indústria de óleo de soja em 1983 na cidade de Rio Verde no parque industrial da COMIGO. A estrutura da cooperativa passou por transformações e incorporou os vários segmentos da agroindústria (Mapa 2: COMIGO Estrutura Física (2005)). Os dados permitem concluir que a COMIGO investiu nos segmentos mais importantes na cadeia do agronegócio da soja, o processamento de sementes, a produção de fertilizantes e na moagem do grão. (COMIGO, 2010)

Desta maneira a cooperativa disputa mercados locais e mundiais, agregando valores à produção local, além de viabilizar grande parte do sistema produtivo da soja, aumentando a lucratividade da cooperativa. Porém ela, não demonstra um retorno econômico aos seus cooperados que muitas vezes compram os insumos de empresas nacionais e multinacionais devido aos preços mais altos praticados pela cooperativa. $\mathrm{O}$ crescimento da produção e da produtividade de grãos na região determinou um crescimento da capacidade armazenadora e de secagem da cooperativa. Por outro lado, a empresa precisou adequar-se às novas 
Campos Neutrais - Revista Latino-Americana de Relações Internacionais Vol. 1, No 2, p. 91-106, Maio- Agosto de 2019

exigências do mercado e dos setores públicos e financeiros. No ano de 2001 , fechou a sua rede supermercados, implantando em seu lugar lojas exclusivas de produtos agropecuários para atender seus cooperados.

Mapa 2:COMIGO: Estrutura Física (2015)

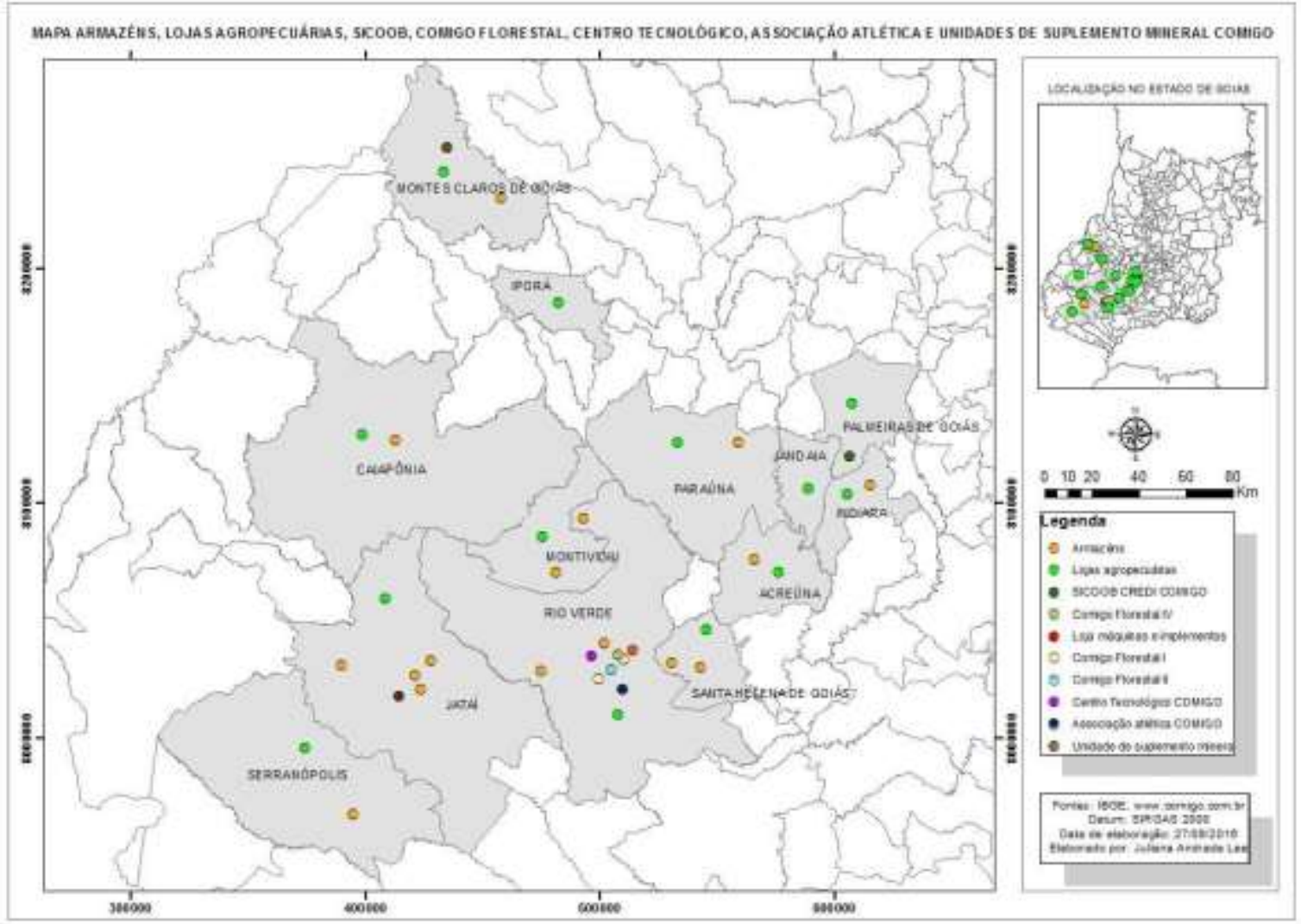

Fonte: www.comigo.com.br. Organizados pelo autor(2016) e elaborado por Juliana A. Lee 
Campos Neutrais - Revista Latino-Americana de Relações Internacionais Vol. 1, No 2, p. 91-106, Maio- Agosto de 2019

Tabela 4: COMIGO - Produto, Capacidade de Produção: 1998, 2006 e 2015

\begin{tabular}{|c|c|c|c|}
\hline Atividade/Produto & 1998 & 2006 & 2015 \\
\hline $\begin{array}{l}\text { Beneficiamento de sementes de } \\
\text { soja }\end{array}$ & $\begin{array}{r}80 \mathrm{mil} \\
\text { sacos/ano }\end{array}$ & $\begin{array}{r}180 \mathrm{mil} \\
\text { sacos/ano }\end{array}$ & $200 \mathrm{mil}$ sacas/ano \\
\hline Descaroçamento de algodão & 7.500@/dia & $7.500 @ / d i a$ & desativado \\
\hline Fábrica de fertilizantes & $90 \mathrm{t} / \mathrm{dia}$ & $100 \mathrm{t} / \mathrm{h}$ & $240 \mathrm{t} / \mathrm{h}$ \\
\hline Fábrica de ração & $40 \mathrm{t} / \mathrm{h}$ & $40 \mathrm{t} / \mathrm{h}$ & $110 \mathrm{t} / \mathrm{h}$ \\
\hline Fábrica de sabão & $20 \mathrm{t} / \mathrm{dia}$ & $20 \mathrm{t} / \mathrm{dia}$ & $\mathrm{s} / \mathrm{d}$ \\
\hline Moageira de Soja & $1.000 \mathrm{t} / \mathrm{dia}$ & $3.500 \mathrm{t} / \mathrm{dia}$ & $5.500 \mathrm{t} / \mathrm{dia}$ \\
\hline $\begin{array}{l}\text { Produção de sal } \\
\text { mineralizado/Suplemento Mineral }\end{array}$ & $21 \mathrm{t} / \mathrm{dia}$ & $36 \mathrm{t} / \mathrm{dia}$ & $350 \mathrm{t} / \mathrm{dia}^{1}$ \\
\hline Refinaria de óleo de soja & $150 \mathrm{t} / \mathrm{dia}$ & $150 \mathrm{t} / \mathrm{dia}$ & $250 \mathrm{t} / \mathrm{dia}$ \\
\hline Unidade de processamento de leite & $\mathrm{s} / \mathrm{d}$ & $120.000 \mathrm{l} / \mathrm{dia}$ & $250.0001 / \mathrm{dia}$ \\
\hline
\end{tabular}

Fonte: Fonte: http://www.comigo.com.br/cadastro.php (acessado em jul.1998, 10 de mai.2006 e 20.set.2015).

Organizado: pelo autor (nov/2015) ${ }^{1}$ Unidade de Jataí 130 t/dia e unidade Montes Claros de Goiás 220 t/dia

O agronegócio no Sudoeste Goiano consolida-se com a instalação das unidades agroindustriais de empresa multinacional de aves-suínos nos municípios de Rio Verde (1997), Jataí (2005) e Mineiros (2007). A unidade agroindustrial de Rio Verde foi planejada para ser a maior planta industrial da empresa e com ela foram introduzidas novas atividades econômicas no campo como a produção de aves e suínos em escala industrial, relações comerciais entre produtores rurais e a agroindústria, uso cada vez maior de incentivos fiscais e de financiamentos públicos, exigências legais sanitárias e ambientais na produção agropecuária, criação de novas associações de produtores rurais, fortalecimento da cadeia produtiva do agronegócio especificamente da cadeia grãos-proteína animal de aves e suínos, construção de novas vias circulação, articulação de modais ferroviário e aeroviário etc.

Faveret Filho e Paula (apud.Helfand e Rezende, 1998, p.31) afirmam que

Nos últimos anos, o padrão tradicional começou a dar mostras de esgotamento. De um lado, os custos logísticos e de gerenciamento de um grande número de integrados (a Perdigão tem cerca de 7 mil) vêm crescendo excessivamente. Levar ração, coletar frangos, prestar assistência técnica e supervisionar contratos de milhares de pequenos integrados - tudo isso é fonte de custos pouco compatíveis com um negócio de margens reduzidas.

Existe a necessidade da redução dos custos operacionais do sistema integrado de aves e suínos por parte empresa processadora de aves e suínos. A saída para a redução dos custos é a 
produção integrada em propriedades rurais de maior porte que possibilitem a existência de granjas com número maior de animais, reduzindo os custos de transporte das rações, das aves e suínos. As grandes extensões das propriedades reduzem os problemas causados pelos dejetos dos animais aumentando a área de deposição e aproveitamento dos mesmos para adubação das lavouras locais de grãos.

As relações do sistema de integração eram inéditas para os produtores rurais que são prestadores de serviços, tendo em vista que os animais alojados em suas granjas são de propriedade da agroindústria. A prestação de serviço é uma atividade tipicamente urbana, a partir dela é nítida a inserção de novas relações de trabalho no campo, por meio do sistema de integração.

As instalações das granjas nas propriedades rurais transformam as paisagens destas unidades produtoras. Os módulos produtores de suínos (Figura 1: Granja de Suínos) (com capacidade para 4 mil animais), SVT (sistema vertical de terminação), composto por 4 galpões, lagoa de dejetos e área de compostagem. O sistema de alimentação é mecanizado, exigindo dos funcionários conhecimento de informática. Os módulos produtores devem estar distanciados no mínimo 200 metros de cursos de águas e das veredas, a 100 metros das reservas legais, e das minas e nascentes a distância ao montante de 400 metros e a jusante de 200 metros. Um dos principais problemas da suinocultura são a deposição e utilização dos dejetos. Estes são nocivos aos mananciais hídricos e solos, quando utilizados de forma incorreta. O sistema de tratamento de dejetos é realizado com armazenamento na fase líquida por um período de 6 meses antes de ser utilizado com fertilizantes nas lavouras de milho, sorgo e pastagens. 
Campos Neutrais - Revista Latino-Americana de Relações Internacionais Vol. 1, No 2, p. 91-106, Maio- Agosto de 2019

Figura 1: Granja de Suínos

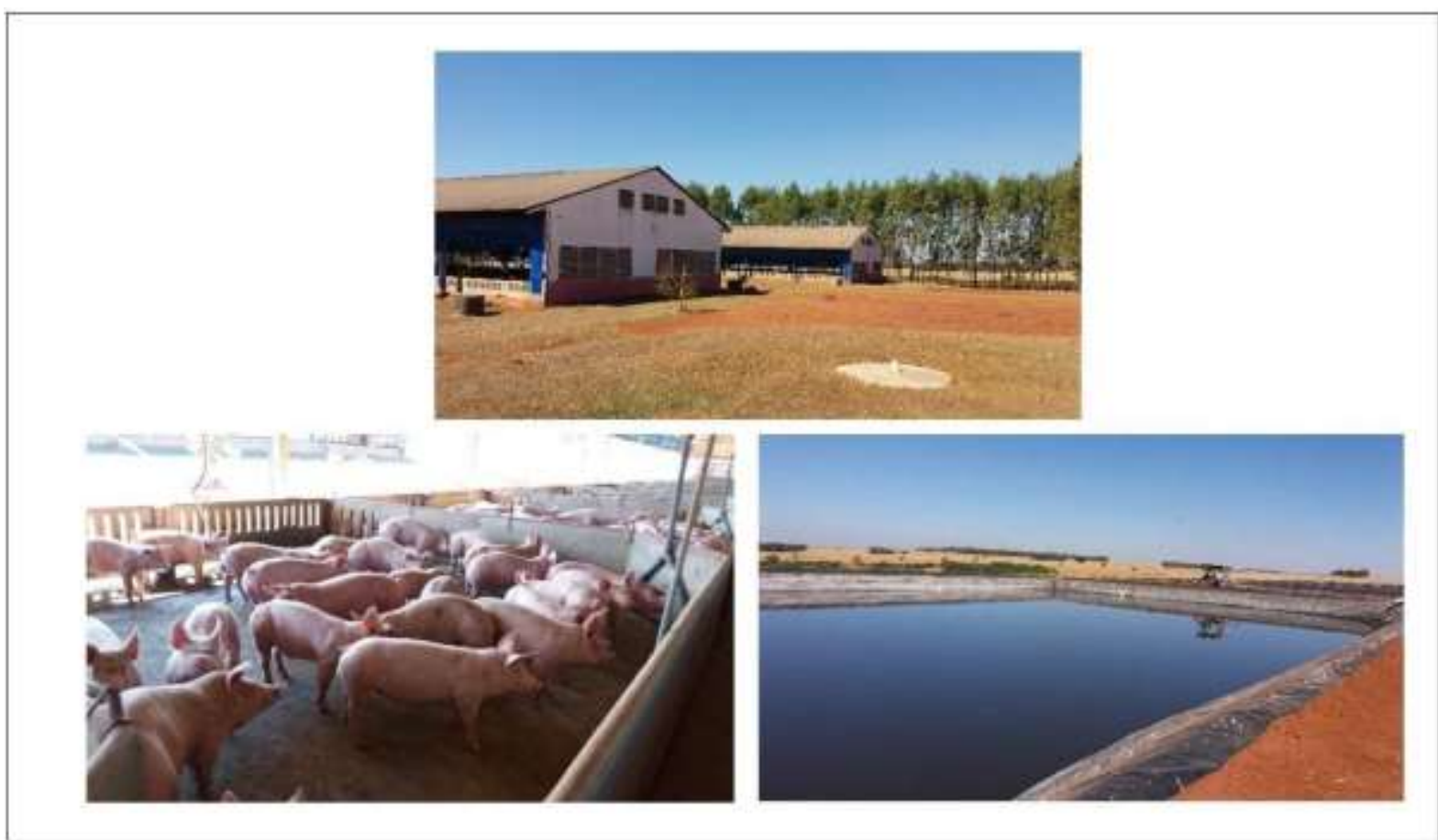

Fonte: Trabalho de Campo município de Rio Verde-GO, julho 2016. Arquivo do autor (2016)

Os produtores do sistema frango de corte (FGO) (Figura 2 Granjas de Frango de Corte) possuem módulos compostos por 4 granjas, que comportam entre 22 a 24 mil frangos. O sistema de alimentação e abastecimento de água também é mecanizado, sem contato manual. As granjas de ovos - SPO (Sistema Produtor de ovos) são composta por 4 galpões com 14mil aves cada e a produção. A unidade agroindustrial de Rio Verde processa 560mil ovos por dia e estes são enviados para outras filiais da empresa em Nova Mutum-MT, Lucas do Rio Verde-MT, Mineiros-GO.

Figura 2: Granjas de Frango de Corte
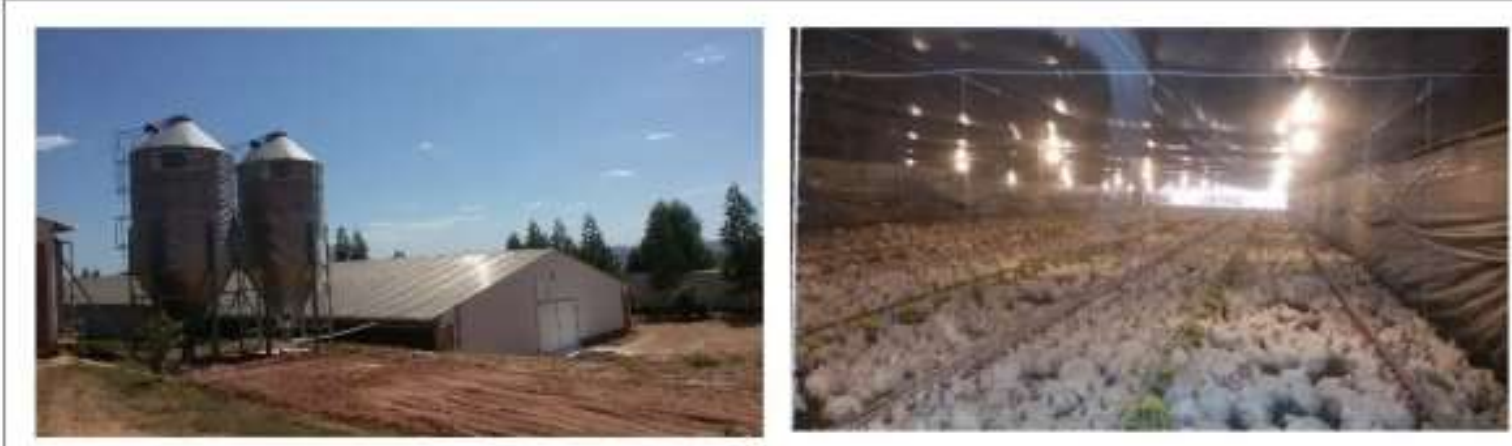

Fonte: Trabalho de Campo município de Mineiros-GO, julho 2016. Arquivo do autor (2016)

De acordo com empresa, o sistema de integração é mais uma alternativa dos produtores rurais tornarem mais eficientes suas unidades produtivas. Não há mais a possibilidade de o produtor rural ser dependente de apenas uma atividade econômica, no caso 
a produção de grãos. Agora a pluriatividade se expande como, por exemplo, o sistema de integração.

Para Oliveira (2003), a instalação da empresa multinacional no município de Rio Verde e no Sudoeste Goiano apresentou benefícios como: a agregação de valores à produção agricola, incremento das exportações, geração de empregos diretos e indiretos no campo e na cidade; favorecimento para o município criar a mentalidade da prática industrial, fomentando o desenvolvimento e crescimento econômico dos setores produtivos urbanos e rurais e propiciando a instalação de novas empresas, como, por exemplo, de embalagens, transportes etc.

\section{Considerações antes de finalizar}

A modernização da agricultura da década de 1970/80 fomentou o processo de industrialização da agricultura com a instalação de unidades agroindustriais as quais criaram dependências das atividades agropecuárias perante o sistema financeiro, do uso dos pacotes tecnológicos e dos agentes comercializadores dessa produção de matérias primas.

O atual estágio de articulação entre as agroindústrias e as atividades agropecuárias é comumente denominado de agronegócio. O Estado e as políticas públicas da metade dos anos de 1990 e início do século XXI fomentam a instalação de unidades industriais e a consolidação da cadeia produtiva agropecuária se fundiu com as industriais. As unidades produtoras de matérias primas se converteram na extensão das indústrias as quais necessitam de produtos padronizados para manter a qualidade e a facilidade de produção e comercialização para os mercados consumidores.

Novas relações econômicas, políticas e socioambientais surgiram com essa etapa do agronegócio. O espaço agrário e urbano do Brasil e consequentemente do Sudoeste Goiano passaram por inúmeras mudanças desde o aumento das áreas de desmatamento, expressivos índices de mecanização da produção agropecuária, introdução de grandes granjas de aves e suínos, urbanização e crescimento urbano entre outros.

\section{Bibliografia}

ALMEIDA, Paulo Roberto de (2004). Planejamento no Brasil: memória histórica. Em: Parcerias Estratégicas, Brasília, v. 18, n. 1, p.157-190. Semestral. Disponível em: http://www.cgee.org.br/arquivos/pe_18.pdf.

ARRAIS, Tadeu Alencar (2013). A produção do território goiano: economia, urbanização, metropolização. Goiânia: Editora UFG. 
Campos Neutrais - Revista Latino-Americana de Relações Internacionais Vol. 1, No 2, p. 91-106, Maio- Agosto de 2019

BARBOSA, Altair Sales (2002). Andarilhos da Claridade: os primeiros habitantes do cerrado. Goiânia: Universidade Católica de Goiás - Instituto do Trópico Subúmido.

BERTRAN, Paulo (1988). Uma Introdução à história econômica do Centro-Oeste do Brasil. Goiânia: UCG.

BRASIL. IBGE (1982). Modernização da agricultura no Sudoeste de Goiás. Rio de Janeiro: IBGE.

CASTRO, Ana Célia e FONSECA, Maria da Graça (1995). A dinâmica do Centro-Oeste. Brasília: IPEA.

CHAUL, NarsFayad (1997). Caminhos de Goiás: da construção da decadência aos limites da modernidade. Goiânia: UFG.

COMIGO (Goiás). História da Comigo. 2010. Disponível em: http://www.comigo.com.br/. Acesso em: 20 out. 2014.

FREDERICO, Samuel (2010). O novo tempo do Cerrado: expansão dos fronts agrícolas e controle do sistema de armazenamento de grãos. São Paulo: Annablume; Fapesp.

HELFAND, Steven M. e REZENDE, Gervásio Castro de (1999). Mudanças na distribuição espacial da produção de grãos, aves e suínos no Brasil: o papel do Centro-Oeste.

Planejamento e Políticas públicas, n. ${ }^{\circ} 19$ - jun de 1999.

IMB (Instituto Mauro Borges de Estatística e Estudos Socioeconômicos) (2013). Meso e Microrregiões do estado de Goiás 2013. . Disponível em: http://www.imb.go.gov.br/pub/mesomicrorregioesibge/2013/mesomicroregioes2013.pdf (2015).

KAGEYAMA, Angela (coordenadora) (1990). O novo padrão agrícola brasileiro: J. In. DELGADO, Guilherme Costa; GASQUES, José Garcia; VERDE, Carlos Monteiro Villa (organizadores). Agricultura e políticaspúblicas. Brasília: IPEA.

LOURDEAU, Antoine (2015). Lithic Technology and Prehistoric Settlement in Central and Northeast Brazil: Definition and Spatial Distribution of the Itaparica Technocomplex.

Paleoamerica, [s.1.], v. 1, n. 1, p.52-67, jan. 2015. Maney Publishing. DOI:

10.1179/2055556314z.0000000005. Disponível em:

http://www.maneyonline.com/doi/pdfplus/10.1179/2055556314Z.0000000005. (12 jan. 2016.)

MATOS, Patrícia Francisca; PESSÔA, Vera Lúcia Salazar (2011). A modernização da agricultura no Brasil e os novos usos do território. Geo Uerj, Rio de Janeiro, v. 22, n. 2, p.290-322, jul. 2011. Semestral. Disponível em: http://www.e-

publicacoes.uerj.br/index.php/geouerj/article/view/2456 (25 set. 2015).

OLIVEIRA, Henrique de. Territorialidades agroindustriais e o reordenamento da dinâmica agrária regional: o caso da Perdigão em Rio Verde/GO. Dissertação (Mestrado em Geografia) - IESA Instituto de Estudos Sócio-ambientais da Universidade Federal de Goiás, Goiânia, 2003. 
Campos Neutrais - Revista Latino-Americana de Relações Internacionais Vol. 1, No 2, p. 91-106, Maio- Agosto de 2019

SANTOS, Milton (2007). O espaço do Cidadão. 7. ed. São Paulo: Editora da Universidade de São Paulo.

SAQUET, Marcos Aurelio (2006). Campo-território: considerações teórico-metodológicas. Campo-Território: Revista de Geografia Agrária, Uberlândia, v. 1, n. 1, p.60-81. Disponível em: http://www.seer.ufu.br/index.php/campoterritorio/article/view/11780/6894 (24.mai.2007)

SEPLAN (Secretaria de Planejamento e Desenvolvimento do Estado de Goiás) (2006).

Regiões de Planejamento do Estado de Goiás. 2006 Disponível https://www.google.com.br/url?sa=t\&rct=j\&q=\&esrc=s\&source=web\&cd=1\&cad=rja\&uact= 8\&ved=0ahUKEwjbnNKqnNPRAhXEHJAKHVvMCbQQFggaMAA\&url=http\%3A\%2F\%2 Fwww.imb.go.gov.br\%2Fdown\%2Fregplan2006.pdf\&usg=AFQjCNG5Hp7JV7Ah_aJgWWq 10TouKJM8yA\&bvm=bv.144224172,d.eWE (14.jan.2012.

TEIXEIRA NETO, Antônio (2009). Pequena história da pecuária goiana. Revista do Instituto Histórico e Geográfico de Goiás, Goiânia, n. 20, p.19-57. Disponível em: http://www.ihgg.org/ArquivosUpload/1/file/Revista do IHGG N 20.pdf (15 fev. 2015) 